\title{
The Role of Heparan Sulfate Proteoglycans in Bacterial Infections
}

\author{
Beatriz García ${ }^{1}$, Iván Fernández-Vega ${ }^{2}$, Olivia García-Suárez ${ }^{3}$, Sonia Castañón ${ }^{4}$ and Luis M Quirós ${ }^{1^{*}}$ \\ ${ }^{1}$ University Institute of Oncology of Asturias and Department of Functional Biology, University of Oviedo, Spain \\ ${ }^{2}$ Department of Pathology, Hospital Universitario de Araba, Spain \\ ${ }^{3}$ Department of Morphology and Cell Biology, University of Oviedo, Spain \\ ${ }^{4}$ Department of Biotechnology, Neiker-Tecnalia Arkaute, Spain
}

"Corresponding author: Luis M Quirós, University Institute of Oncology of Asturias, and Department of Functional Biology, University of Oviedo, Spain, Tel: +34 985103560; E-mail: quirosluis@uniovi.es

Rec Date: July 22, 2014, Acc date: August 24, 2014, Pub date: August 26, 2014

Copyright: (c) 2014 Garcia B, et al. This is an open-access article distributed under the terms of the Creative Commons Attribution License, which permits unrestricted use, distribution, and reproduction in any medium, provided the original author and source are credited.

\begin{abstract}
The adhesion of bacteria to target tissues is frequently a necessary first step in pathogenesis. Blocking of such adhesion can provide an efficient way of interfering in bacterial infections. A wide spectrum of microbial pathogens bind to cell surface heparan sulfate proteoglycans in order to facilitate adherence, attachment and cellular entry, as well as to evade defense mechanisms. Knowledge of these mechanisms is important for the development of novel antimicrobial agents and new therapies.
\end{abstract}

Keywords: Proteoglycan; Glycosaminoglycans; Heparan sulphate; Microbial pathogenesis

\section{Bacterial Adhesion to Cells}

Bacterial infections constitute a major global health problem. Adhesion of bacteria to eukaryotic cells is often an important first step in the pathogenic process, and this early establishment of physical contact between pathogen and host can be used as a target for the development of novel ways of interfering with bacterial infections.

Over recent years, new insights have emerged regarding the mechanism and biological significance of such interactions. In its simplest form, microbial adhesion demands the participation of two factors: a receptor and a ligand. The typical bacterial ligands, called adhesins, are macromolecular components of the bacterial cell surface which interact with specific target receptors on the host cell. In reality, this process may be complex and for a single microbe can involve redundancy or the possession of multiple adhesins or mechanisms of attachment. These mechanisms can co-operate to create high affinity interactions and increase bacterial adhesion, and the first adhesive event may trigger the expression of receptors for additional adhesins in the target cell [1-7]. Moreover, some bacteria may use phase variation, displaying on-off expression of different surface structures for immune evasion. Hence the importance of the diversity of receptor targeting mechanisms to the success of adherence and subsequent pathogenesis is evident.

Different Gram-negative bacteria can display several components, such as the hair-like adhesive structures referred to as pili or fimbriae, which are constituted by proteins on the surface that can behave as adhesins for specific adherence (Figure 1). One example of this is type 1 fimbriae, which are widely expressed by Escherichia coli and are used by uropathogenic strains to attach to the urinary tract. These fimbriae belong to a class of fibrillar adhesion structures assembled through the chaperone/usher pathway [8-10]. Gram-positive bacteria also show a great variety of factors involved in adherence, like matrixbinding proteins called microbial surface components recognizing adhesive matrix molecules (MSCRAMMs) [11,12]. These proteins bind to extracellular matrix proteins such as fibronectin, collagen vitronectin and laminin among others.

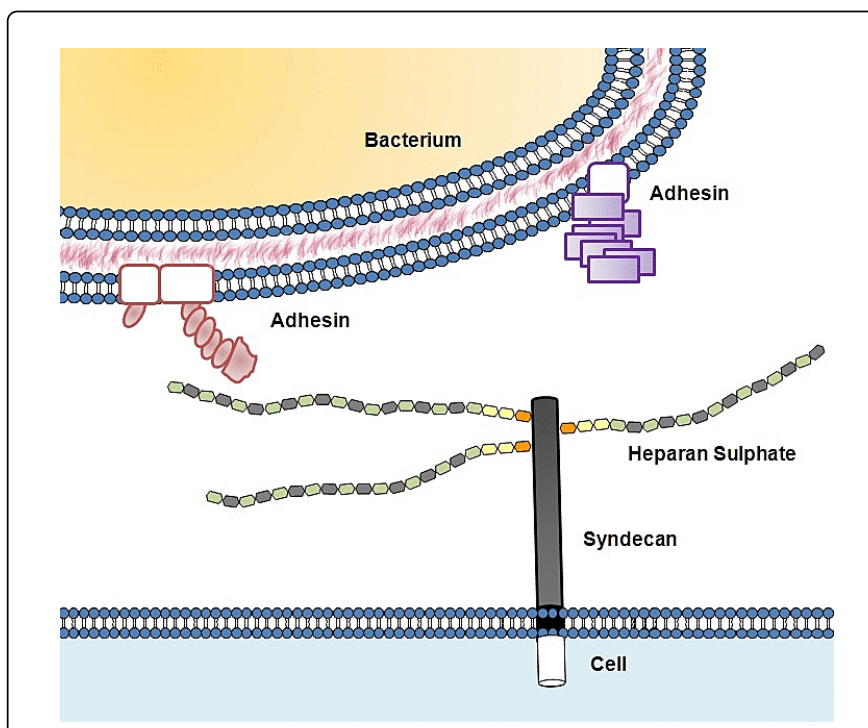

Figure 1: Adhesion of bacteria to target cells mediated by proteoglycans. Schematic representation of adhesins on the outer membrane of Gram-negative bacteria, and structure of a proteoglycan on the cell surface of a eukaryotic cell. Heparan sulfate proteoglycans are commonly arranged on the cell surface and in the extracellular matrix. Cell-associated proteoglycans include glycosyl-phosphatidylinositol-anchored glypicans and integral membrane syndecans (as the one shown in this figure).

As regards eukaryotic cellular receptors, they are ubiquitous on the surface of epithelial cells, and capable of displaying great variability, which accounts for the organotropism proven in some bacterial adhesions. This is the case of proteoglycans (PGs), glycoconjugates 
involved in the attachment of a wide spectrum of microbial pathogens, including viruses, bacteria and parasites. PGs can also be involved in other steps of pathogenicity, such as cellular invasion or evasion of defense mechanisms [13-17], and they are therefore proposed as potential targets for novel prophylactic and therapeutic approaches.

\section{Structure and Function of Heparan Sulfate Proteoglycans}

PGs are composed of different core proteins, post-translationally modified with anionic polysaccharides called glycosaminoglycans (GAGs). GAGs are mainly composed of repeating disaccharides containing acetylated aminosugar moieties and uronic acid [18]. Differences in the type of monosaccharides in the repeating unit, as well as in their sulfation patterns, result in various types of GAGs [19]. Heparan sulfate (HS) is a widespread form of sulfated GAG, being present in all cell types and tissues at the extracellular and cellular levels (Figure 1). HS consists of repeating disaccharide units of $\mathrm{N}$ acetylglucosamine (GlcNAc) and hexuronic acid residues. HS chains are synthesized in the Golgi apparatus by enzymes that initially polymerize alternating GlcNAc and glucuronic acid (GlcA) residues [19]. The resulting disaccharide repeats are then variously modified by interdependent reactions that do not occur uniformly along the chain. First, N-deacetylase/sulfotransferases (NDSTs) catalyze the Ndeacetylation, usually followed by the N-sulfation of the GlcNAc units. It is worth remarking that these reactions principally occurs in domains of, usually, 3-6 disaccharides in length (known as Sdomains), in which the GlcA may subsequently be C5-epimerized into iduronic acid (IdoA), this is followed by various O-sulfations, frequently at the $\mathrm{C} 6$ and $\mathrm{C} 2$ position of the glucosamine and IdoA residues respectively, and more rarely at the $\mathrm{C} 3$ of glucosamine and $\mathrm{C} 2$ of GlcA [20]. HSPGs bind to a large number of ligands and, although some bind directly to core proteins, the vast majority interact with sulfated domains within HS chains. Differences in the degree of epimerization and sulfation patterning during HS biosynthesis generate very high variability and, as such, provide HS chains with various different docking sites for the various ligands of the polysaccharide [21].

A broad range of both normal and pathological functions have been ascribed to HSPGs, including cell adhesion and migration, organization of the extracellular matrix (ECM), regulation of proliferation, differentiation and morphogenesis, cytoskeleton organization, tissue repair, inflammation, vascularization and cancer metastasis, the function ultimately depending on the fine structure of the chains [21-26]. Specific sets of variably modified disaccharides, usually within the sulfated domains, define binding sites for a multitude of specific ligands such as cytokines, chemokines, growth factors, enzymes and enzyme inhibitors, and ECM proteins [23,27,28]. HSPGs fall into three groups according to their location: membrane HSPGs, mainly syndecans and glypicans; secreted extracellular matrix HSPGs including agrin, perlecan and type XVIII collagen; and serglycin which is usually located intracellularly in secretory vesicles. Membrane HSPGs cooperate with integrins and other cell adhesion receptors to facilitate cell-ECM attachment, cell-cell interactions, and cell motility $[29,30]$.

\section{Involvement of Heparan Sulfate Proteoglycans in Bacterial Pathogenesis}

Many pathogens make use of HSPGs as essential factors in their virulence activity, including both Gram-negative and Gram-positive bacteria, although the molecular and cellular strategies involved vary significantly among microorganisms. HSPGs can provide specific sites for adhesion and, subsequently, they may be involved in internalisation of some microorganisms and in other mechanisms related to pathogenicity.

The sexually transmitted disease gonorrhea is caused by the Gramnegative bacterium Neisseria gonorrhoeae which binds to syndecans on the epithelium surface thanks to the adhesin OpaA. [31,32]. Both syndecan- 1 and -4 can act as receptors in this case due to their overexpression in HeLa cells increasing the adhesion of bacteria $[31,33]$. Upon binding, intracellular signaling cascades are activated by the cytoplasmic domain of the syndecans, which have been shown to be essential for invasion using HeLa cell mutants in these domains [33]. In addition to the binding step, HSPGs play an important role in the internalization of $\mathrm{N}$. gonorrheae, as in HEp-2 human laryngeal carcinoma cells, where the complex syndecan-OpaA uses fribronectin to bind to $\beta 1$ integrin receptors, which mediate the internalization [32].

The Gram-negative bacterium Helicobacter pylori appears adhered to gastric mucosa, and it has been recognized as the main cause of gastritis and ulcers and it is classified as a class I carcinogenic agent by the International Agency for Research on Cancer due to its association with gastric carcinogenesis [34-36]. HS chains on the surface of gastric cells are mainly responsible for the adhesion of $H$. pylori, mediated by the recognition of HS by the outer-membrane proteins of the bacteria [37-40]. The different strains of the bacterium have varying degrees of pathogenicity, depending, among other things, on the presence of the cag pathogenicity island, which encodes a type IV secretion system, and the cytotoxic protein CagA [41,42]. CagA is directly injected into the bacteria-attached host gastric epithelial cell via the bacterial type IV secretion system. The translocated protein CagA deregulates intracellular signaling pathways, leading to various effects, including the activation of the NF-kB signaling pathway. NF- $\mathrm{kB}$ transcription factor binds to a specific sequence within the promoter of the human syndecan-4 gene to enhance its expression [41,42-48]. This upregulation of the expression of syndecan- 4 has been described in human gastric mucosa and in the gastric carcinoma epithelial cell lines MKN45 and AGS and it is dependent on the presence of cag in the genome infecting strain [49]. Besides the adhesion of the bacteria to the cell surface, $H$. pylori secrete many proteins that are important for both initial colonization and persistence in the gastric mucosa [50]. HS is also involved in the binding of secreted factors, as is the case in the attachment and entry of cytotoxin vacA, an important pathogenic factor that causes extensive vacuolation that eventually leads to cell death [51].

Within the group of Gram-negative bacteria there are various examples of intracellular pathogens, such as the members of the genus Chlamydia, whose adherence and entry into human cells depends on HSPGs. These microorganisms show a unique developmental cycle characterized by two functionally and morphologically distinct bacterial forms, the elementary body (EB) and the reticulate body (RB) [52]. Infection is initiated by the metabolically inactive EB which then differentiates into the larger, metabolically active RB after endocitosis. HSPGs mediate the initial attachment of several species of Chlamydia, 
to different degrees depending on the species, strain, and host cell [53]. C. trachomatis presents several serovars that produce diverse infections and show different HS dependencies both in vivo and in vitro; the interaction of serovar L2 with cells is highly reduced by HS and heparin, although serovar E binding is not affected [54,55]. Another route for $C$. trachomatis to interact with cells is mediated by fibroblast Growth Factor 2 (FGF2) which binds directly to EBs, facilitating the interaction between the bacterium and FGF receptor (FGFR). The receptor is locally activated and contributes to bacterial uptake into non-phagocytic cells [56]. FGF2 is also capable of interact with HS from the host cell itself and furthermore its binding to EB may involve synergistic interactions with $\mathrm{OmcB}$, an EB outer membrane protein that also uses HS from the epithelium as receptor [56-58]. Infection stimulates an increase in production of FGF2, enhancing the subsequent cycles of infection by the bacteria. FGF2 may play additional roles in the pathogenesis of chlamydial infection by potentiating the inflammatory response, by inhibiting apoptosis, or by modulating gene expression [56]. Another species of this genus, $C$. pneumoniae, also uses HS chains as receptor to bind to the cell surface. The interaction of this microorganism with HEp-2 host cells, which present high levels of HS and strong expression of PG-core protein genes, can be inhibited by HS and heparin although not completely, which suggests that both attachment and entry may be mediated by other co-receptors $[59,60]$. Nevertheless, $C$. pneumoniae is also able to infect lymphoid Jurkat cells and CD4+ lymphocytes, which poorly express PG-core proteins and present minimal expressions of GAGs, implying the presence of attachment irrespective of the presence of HS, even if the adhesion is inhibited by HS, indicating that other molecules are implicated [60].

Another example of a Gram-negative obligate intracellular pathogen is Borrelia burgdorferi, a spirochete bacterium that is well known as the causative agent of Lyme disease. B. burgdorferi infects multiple tissues, such as the heart, joint, skin, and nervous system, by means of different GAG species depending on the tissue. In HeLa cells, heparin, HS, and dermatan sulfate (DS) reduced the attachment of virulent B. burgdorferi strain 297, and these three GAGs are also implicated in binding to neuronal and primary telencephalon cell lines [61,62]. However, heparin and HS play the most critical role for spirochetal binding to primary endothelial cells and Vero cells, while DS mediates attachment to Human Embryonic Kidney 293 cells [61,62]. GAGs are recognized by multiple $B$. burgdorferi surface proteins depending on the cell type: Bgp (heparin-binding), DbpA and DbpB (GAG binding), and BBK32 (fibronectin and GAGs), each shows binding specificity to different cells and GAGs $[63,64]$.

HSPGs have essential roles in microbial recognition, interaction, adherence and internalization through a wide range of mechanisms, and may be have other roles such as signaling cascades, gene expression regulation or co-receptors of many different factors, altering cells and allowing the invasion to spread [16,65]. Moreover, membrane-bound PGs can also function as soluble molecules since the intact extracellular domain can be released from the cell surface by an enzymatic cleavage mechanism known as ectodomain shedding. These soluble PGs can function as autocrine or paracrine effectors, and can also be used as a mechanism of pathogenesis by a broad range of infectious and noninfectious diseases $[65,66]$.

Gram-negative opportunistic pathogen Pseudomonas aeruginosa, the major cause of burn infections and cystic fibrosis lung disease, uses a combination of virulence strategies, including shedding of HSPGs. It induces syndecan-1 shedding in vitro and in vivo via its virulence factor LasA by means of a mechanism involving metalloproteinases [67]. Syndecan-1 shedding is important for $P$. aeruginosa infection, since shedding antagonists attenuates its virulence as demonstrated by the fact that syndecan-1 null mice resist the infection [67]. Another virulence mechanism used by $P$. aeruginosa involves the degradation of decorin by extracelular proteinases, elastase and alkaline proteinase, which releases DS chains. The released DS binds to neutrophil-derived a-defensin, and this binding completely neutralizes its bactericidal activity [68]. In addition $P$. aeruginosa presents different virulence factors in its outer membrane to bind to non-polarised and untight epithelial respiratory cells. Among them, pilin ligands interact with GalNAc $\beta 1-4 \mathrm{Gal}$ moiety of asialoGM1 glycolipids, infrequent in normal pulmonar epithelium but increased in cystic fibrosis one; while non pilus ligands adhere to cells through HSPGs, which can be inhibited by heparin $[69,70]$. In polarized epithelium $P$. aeruginosa recognizes distinct receptors on the apical and basolateral surfaces; the microorganism binds specifically to MDCK cells and colocalizes with HS-rich areas at the basolateral membrane, although it interacts with complex N-glycans on the apical surface [71].

HSPGs are also a critical factor in the pathogenicity of a wide range of Gram-positive bacterial pathogens, which present distinct mechanisms of adhesion to cell surfaces as well as shedding mechanisms. Staphylococcus aureus is a common cause of various infections such as corneal keratitis, although this bacterium can be found as part of the normal microbiota, where it is not pathogenic. In corneal infections, syndecan- 1 has been proven not to play any role in adherence or attachment to corneal epithelium in mouse and rabbit models, the key host determinants that mediate the initial attachment being collagen and/or fibronectin in the latter [72]. Nevertheless, $S$. aureus is able to induce the shedding of syndecan-1 ectodomain through $\alpha$ - and $\beta$-toxin, both in vitro and in mice models, which inhibits neutrophil-mediated bacterial killing mechanisms in an HSdependent manner, thereby increasing the pathogenesis process and bacterial survival. Shedding is also involved in increasing the damage and inflamation process by generating gradients of quimioatractors [72]. However, in intestinal epithelium HSPGs are involved in $S$. aureus internalization and colonization in mice models, where the bacterium can be internalized by non-professional phagocytes through interaction with HS moieties of cell-surface HSPGs independent of fibronectin binding [73].

Mycobacterium tuberculosis, the Gram-positive bacterium that causes tuberculosis, infects phagocytes and pulmonar epithelial cells, but adhesion only happens in the latter, being mediated predominantly by heparin-binding haemagglutinin adhesin (HBHA). Extrapulmonary dissemination is also mediated by this adhesin, whose binding to cell surface HSPGs triggers intracellular signaling mechanisms that are critical for the transcytosis of $M$. tuberculosis, leading to the dissemination of the infection [74].

Listeriosis is a serious infection caused by eating food contaminated with the Gram-positive intracellular pathogen Lysteria monocytogenes which is able to invade a wide range of cells, such as macrophages and nonphagocytic cells, by inducing its own internalization $[75,76]$. In intestinal cell lines heparin and HS inhibit adherence and internalization of $L$. monocytogenes in cells with prominent syndecan-1 expression such as HT-29, but not in Caco2 which displays low syndecan-1 expression, thus demonstrating the important role of this HSPG in pathogenicity [77,78]. This bacterium has several membrane proteins involved in adherence, one of which is ActA which interacts via HSPG with the cell surface with low affinity and 
mediates migration into and between nonphagocytic cells by exploiting host cell cytoskeletal machinery $[75,76]$. On the other hand, in nonphagocytic cells L. monocytogenes expresses two invasins, InlA and InlB, which induce bacterial internalization. During invasion of polarized epithelial cells, the protein InlA takes advantage of the adhesion molecule E-cadherin and the adherens junction machinery to bind and invade, while in non-polarized epithelial cells InlB interacts with the hepatocyte growth factor receptor Met, which interacts with GAGs to induce endocytosis of the receptor and also to facilitate internalization of the bacteria [79].

Gram positive bacteria from the genus Streptococcus are classified into several groups that cause different types of infections mediated by interaction with HSPGs. A representative member of the Group A Streptococcus is $S$. pyogenes, the etiologic agent of a variety of human diseases like pharyngitis and impetigo [80]. S. pyogenes expresses a wide variety of proteins on its surface to mediate interactions with host cells from different tissues, among them $M$ proteins, which provide phagocytosis resistance and bind to DS and HS of cell surfaces [80]. Another member of group A Streptococcus, S. pneumoniae, is the most important pathogen in meningitis in older children and adults. This microorganism binds to heparin, HS and chondroitin 4-sulfate in the colonization of respiratory mucosal epithelial cells causing pneumonia [81]. S. agalactiae is included in group B of Streptococcus, and is the cause for the majority of cases of pediatric infectious diseases. This pathogen binds to HSPGs on the cellular surface through alpha-C protein (ACP), which mediates the internalization of bacteria into ME180 cervical epithelial cells, involving Rho GTPasedependent actin rearrangements [82]. $S$. agalactiae is the causative agent responsible for neonatal bacterial meningitis, and some studies have shown that ACP uses GAGs as receptors to adhere to and cross the blood-brain barrier and invade the central nervous system [83]. Chain length and negative charge on the GAGs are both important to provide the binding forces between ACP and GAGs, as well as the GAG species involved in the adhesion, such that GAG expression patterns may determine the nature and efficiency of bacterial dissemination during infection [83].

The intestinal tract is a source of many pathogens, including the Gram-positive bacterium Enterococcus faecalis which is a major cause of nosocomial infections affecting different tissues [16]. In Caco2 cells, HSPGs act as receptors in the early stages of infections by enterococci, and HS and heparin are able to inhibit this binding [84]. HSPGs are not only implied in recognition and adherence, but also in the internalization of bacteria in professional and nonprofessional phagocytes, involving the reorganization of microtubules and activation of protein kinases. The microorganism can resist specific killing mechanisms inside these phagocytes and so invasion and dissemination progresses [85]. Urinary tract infections are usually caused by E. faecalis, and contrary to what happens in adherence to other epithelium, neither wild-type bacteria nor glycolipid mutant's use GAGs as receptors to bind to uroepitelial cells [86].

Besides pathogens, it is important to study the mechanisms that normal human microbiota use for adhering to and colonizing cells because of, among other reasons, the competition with pathogenic bacteria for the same attachment sites on these cells. Human microbiota is composed mainly of members of the genus Lactobacillus. Many studies have been conducted on the factors involved in the adherence of Lactobacillus to different epithelial cells including intestinal or vaginal epithelium [87-90], and GAGs have been described as receptors for adhesion. An adhesin that plays a fundamental role in attachment of $L$. salivarus Lv72 is OppA, a soluble binding protein of an $\mathrm{ABC}$ transporter system that bind to $\mathrm{HS}$ and CSC from the epithelial surface [17]. PGs and GAGs are widespread molecules but some of their functions are still unclear. Not only do pathogens of different origins take advantage of these molecules in a direct wary for infection and invasion, but they can also play different roles in certain alterations. In inflammatory Bowel disease or colitis severe intestinal inflammation occurs due to the immune responses to toxic compounds such as endotoxins and enzymes produced by instestinal microbiota. During this process, degradative GAGs enzymes are induced in the microbiota, and they act on the intestinal mucosa GAGs, releasing D-galatosamine and D-glucosamine which are cytotoxic against the cells. Treatment with antibiotics mitigates colitis by inhibiting these bacteria [91].

In addition, increased levels of circulating GAGs are found in septic shock patients and the levels are correlated with mortality. These released GAGs may be attributed to shedding of endothelial cells stimulated by proinflammatory substances, especially syndecan-1 which is related to inflammation and promotes leukocyte adherence. Shedding of GAGs plays a role in the dysregulation of the endothelial function, resulting in increased permeability in septic shock [92].

HSPG-pathogen interactions could reveal previously unknown functions for these molecules. Knowledge of the function and involvement of PGs is important for the development of novel antimicrobial agents and therapies for infections and other diseases.

\section{Conclusions}

HSPGs comprise a reduced and specific group of proteins that display an enormous structural diversity in their GAG chains which, along with their ubiquity in all cell types and in the ECM, allow them to play an essential role in the interaction between bacterial pathogens and the surface of host cells. Indeed, many pathogenic microorganisms use these molecules not only as specific receptors for adherence and attachment, but also in bacterial internalization and invasion during the infective process. Furthermore, they are involved in different alterations independent of the presence of pathogens.

\section{References}

1. Virji M (2009) Ins and outs of microbial adhesion. Top Curr Chem 288: $139-156$.

2. Griffiths NJ, Bradley CJ, Heyderman RS, Virji M (2007) IFN-gamma amplifies NfkappaB-dependent Neisseria meningitidis invasion of epitelial cells via specific upregulation of CEA-related cell adhesion molecule. Cell Micriobiol 9: 2968-2983.

3. Virji M, Makepeace K, Peak IR, Ferguson DJ, Jennings MP, et al. (1995) Opc- and pilus-dependent interactions of meningococci with human endothelial cells: molecular mechanisms and modulation by surface polysaccharides. Mol Microbiol 18: 741-754.

4. Ishibashi Y, Nishikawa A (2003) Role of nuclear factor-kappa B in the regulation of intercellular adhe-sion molecule I after infection of human bronchial epitelial cells by Bordetella pertussis. Microb Pat-hog 35: 169-177.

5. Sandros J, Tuomanen E (1993) Attachment factors of Bordetella pertussis: mimicry of eukaryotic cell recognition molecules. Trends Microbiol 1: 192-196.

6. Rao SP, Gehlsen KR, Catanzaro A (1992) Identification of a beta 1 integrin on Mycobacterium avium-Mycobacterium intracellulare. Infect Immun 60: 3652-3657. 
7. Kenny B, DeVinney R, Stein M, Reinscheid DJ, Frey EA, et al. (1997) Enteropathogenic E. coli (EPEC) transfers its receptor for intimate adherence into mammalian cells. Cell 91: 511-520.

8. Knight SD, Bouckaert J (2009) Structure, function, and assembly of type 1 fimbriae. Top Curr Chem 288: 67-107.

9. Duguid JP, Anderson ES (1967) Terminology of bacterial fimbriae, or pili, and their types. Nature 215: 89-90.

10. Hung DL, Hultgren SJ (1998) Pilus biogenesis via the chaperone/usher pathway: an integration of structure and function. J Struct Biol 124: 201-220.

11. Ohlsen K, Oelschlaeger TA, Hacker J, Khan AS (2009) Carbohydrate receptors of bacterial adhesins: implications and reflections. Top Curr Chem 288: 17-65.

12. Patti JM, Allen BL, McGavin MJ, Höök M (1994) MSCRAMM-mediated adherence of microorganisms to host tissues. Annu Rev Microbiol 48 585-617.

13. Bernfield M, Kokenyesi R, Kato M, Hinkes MT, Spring J, et al. (1992) Biology of the syndecans: a family of transmembrane heparan sulfate proteoglycans. Annu Rev Cell Biol 8: 365-393.

14. Rostand KS, Esko JD (1997) Microbial adherence to and invasion through proteoglycans. Infect Immun 65: 1-8.

15. Spillmann D (2001) Heparan sulfate: anchor for viral intruders? Biochimie 83: 811-817.

16. Chen Y, Götte M, Liu J, Park PW (2008) Microbial subversion of heparan sulfate proteoglycans. Mol Cells 26: 415-426.

17. Martín R, Martín C, Escobedo S, Suárez JE, Quirós LM (2013) Surface glycosaminoglycans mediate adherence between HeLa cells and Lactobacillus salivarius Lv72. BMC Microbiol 13: 210.

18. Gallagher JT (1989) The extended family of proteoglycans: social residents of the pericellular zone. Curr Opin Cell Biol 1: 1201-1218.

19. Prydz K, Dalen KT (2000) Synthesis and sorting of proteoglycans. J Cell Sci 113 Pt 2: 193-205.

20. Sugahara K, Kitagawa H (2002) Heparin and heparan sulfate biosynthesis. IUBMB Life 54: 163-175.

21. Vivès RR, Seffouh A, Lortat-Jacob H (2014) Post-Synthetic Regulation of HS Structure: The Yin and Yang of the Sulfs in Cancer. Front Oncol 3: 331.

22. Salmivirta M, Lidholt K, Lindahl U (1996) Heparan sulfate: a piece of information. FASEB J 10: 1270-1279.

23. Bernfield M, Götte M, Park PW, Reizes O, Fitzgerald ML, et al. (1999) Functions of cell surface heparan sulfate proteoglycans. Annu Rev Biochem 68: 729-777.

24. Rapraeger A, Jalkanen M, Bernfield M (1986) Cell surface proteoglycan associates with the cytoskeleton at the basolateral cell surface of mouse mammary epithelial cells. J Cell Biol 103: 2683-2696.

25. Dreyfuss JL, Regatieri CV, Jarrouge TR, Cavalheiro RP, Sampaio LO, et al. (2009) Heparan sulfate proteoglycans: structure, protein interactions and cell signaling. An Acad Bras Cienc 81: 409-429.

26. Schmidt G, Robenek H, Harrach B, Glössl J, Nolte V, et al. (1987) Interaction of small dermatan sulfate proteoglycan from fibroblasts with fibronectin. J Cell Biol 104: 1683-1691.

27. Kirn-Safran C, Farach-Carson MC, Carson DD (2009) Multifunctionality of extracellular and cell surface heparan sulfate proteoglycans. Cell Mol Life Sci 66: 3421-3434.

28. Schaefer L, Schaefer RM (2010) Proteoglycans: from structural compounds to signaling molecules. Cell Tissue Res 339: 237-246.

29. Sarrazin S, Lamanna WC, Esko JD (2011) Heparan sulfate proteoglycans. Cold Spring Harb Perspect Biol 3.

30. DeAngelis PL (2012) Glycosaminoglycan polysaccharide biosynthesis and production: today and tomorrow. Appl Microbiol Biotechnol 94: 295-305.

31. Grassmé H, Gulbins E, Brenner B, Ferlinz K, Sandhoff K, et al. (1997) Acidic sphingomyelinase mediates entry of $\mathrm{N}$. gonorrhoeae into nonphagocytic cells. Cell 91: 605-615.
32. van Putten JP, Duensing TD, Cole RL (1998) Entry of OpaA+ gonococci into HEp-2 cells requires concerted action of glycosaminoglycans, fibronectin and integrin receptors. Mol Microbiol 29: 369-379.

33. Freissler E, Meyer auf der Heyde A, David G, Meyer TF, Dehio C (2000) Syndecan- 1 and syndecan- 4 can mediate the invasion of OpaHSPGexpressing Neisseria gonorrhoeae into epithelial cells. Cell Microbiol 2: 69-82.

34. Watanabe T, Tada M, Nagai H, Sasaki S, Nakao M (1998) Helicobacter pylori infection induces gastric cancer in mongolian gerbils. Gastroenterology 115: 642-648.

35. Fujioka T, Honda S, Tokieda M (2000) Helicobacter pylori infection and gastric carcinoma in animal models. J Gastroenterol Hepatol 15 Suppl: D55-59.

36. Zheng Q, Chen XY, Shi Y, Xiao SD (2004) Development of gastric adenocarcinoma in Mongolian gerbils after long-term infection with Helicobacter pylori. J Gastroenterol Hepatol 19: 1192-1198.

37. Wadström T, Hirmo S, Borén T (1996) Biochemical aspects of Helicobacter pylori colonization of the human gastric mucosa. Aliment Pharmacol Ther 10 Suppl 1: 17-27.

38. Utt M, Wadström T (1997) Identification of heparan sulphate binding surface proteins of Helicobacter pylori: inhibition of heparan sulphate binding with sulphated carbohydrate polymers. J Med Microbiol 46: $541-546$

39. Guzman-Murillo MA, Ruiz-Bustos E, Ho B, Ascencio F (2001) Involvement of the heparan sulphate-binding proteins of Helicobacter pylori in its adherence to HeLa S3 and Kato III cell lines. J Med Microbiol 50: 320-329.

40. Ruiz-Bustos E, Ochoa JL, Wadström T, Ascencio F (2001) Isolation and characterisation of putative adhesins from Helicobacter pylori with affinity for heparan sulphate proteoglycan. J Med Microbiol 50: 215-222.

41. Odenbreit S, Püls J, Sedlmaier B, Gerland E, Fischer W, et al. (2000) Translocation of Helicobacter pylori CagA into gastric epithelial cells by type IV secretion. Science 287: 1497-1500.

42. Figueiredo C, Machado JC, Pharoah P, Seruca R, Sousa S, et al. (2002) Helicobacter pylori and interleukin 1 genotyping: an opportunity to identify high-risk individuals for gastric carcinoma. J Natl Cancer Inst 94: 1680-1687.

43. Tanaka J, Suzuki T, Mimuro H, Sasakawa C (2003) Structural definition on the surface of Helicobacter pylori type IV secretion apparatus. Cell Microbiol 5: 395-404.

44. Hatakeyama M (2004) Oncogenic mechanisms of the Helicobacter pylori CagA protein. Nat Rev Cancer 4: 688-694.

45. Bourzac KM, Guillemin K (2005) Helicobacter pylori-host cell interactions mediated by type IV secretion. Cell Microbiol 7: 911-919.

46. Brandt S, Kwok T, Hartig R, König W, Backert S (2005) NF-kappaB activation and potentiation of proinflammatory responses by the Helicobacter pylori CagA protein. Proc Natl Acad Sci U S A 102: 9300-9305.

47. Zhang Y, Pasparakis M, Kollias G, Simons M (1999) Myocyte-dependent regulation of endothelial cell syndecan-4 expression. Role of TNF-alpha. J Biol Chem 274: 14786-14790.

48. Smith MF Jr, Novotny J, Carl VS, Comeau LD (2006) Helicobacter pylori and toll-like receptor agonists induce syndecan-4 expression in an NFkappaB-dependent manner. Glycobiology 16: 221-229.

49. Magalhães A, Marcos NT, Carvalho AS, David L, Figueiredo C, et al. (2009) Helicobacter pylori cag pathogenicity island-positive strains induce syndecan-4 expression in gastric epithelial cells. FEMS Immunol Med Microbiol. 56: 223-232.

50. Palframan SL, Kwok T, Gabriel K (2012) Vacuolating cytotoxin A (VacA), a key toxin for Helicobacter pylori pathogenesis. Front Cell Infect Microbiol 2: 92

51. Utt M, Danielsson B, Wadström T (2001) Helicobacter pylori vacuolating cytotoxin binding to a putative cell surface receptor, heparan sulfate, studied by surface plasmon resonance. FEMS Immunol Med Microbiol 30: 109-113. 
52. Moulder JW (1991) Interaction of chlamydiae and host cells in vitro. Microbiol Rev 55: 143-190.

53. Zaretzky FR, Pearce-Pratt R, Phillips DM (1995) Sulfated polyanions block Chlamydia trachomatis infection of cervix-derived human epithelia. Infect Immun 63: 3520-3526.

54. Davis CH, Wyrick PB (1997) Differences in the association of Chlamydia trachomatis serovar E and serovar L2 with epithelial cells in vitro may reflect biological differences in vivo. Infect Immun 65: 2914-2924.

55. Taraktchoglou M, Pacey AA, Turnbull JE, Eley A (2001) Infectivity of Chlamydia trachomatis serovar LGV but not $\mathrm{E}$ is dependent on host cell heparan sulfate. Infect Immun 69: 968-976.

56. Kim JH, Jiang S, Elwell CA, Engel JN (2011) Chlamydia trachomatis coopts the FGF2 signaling pathway to enhance infection. PLoS Pathog 7: e1002285.

57. Stephens RS, Koshiyama K, Lewis E, Kubo A (2001) Heparin-binding outer membrane protein of chlamydiae. Mol Microbiol 40: 691-699.

58. Fechtner T, Stallmann S, Moelleken K, Meyer KL, Hegemann JH (2013) Characterization of the interaction between the chlamydial adhesin OmcB and the human host cell. J Bacteriol 195: 5323-5333.

59. Wuppermann FN, Hegemann JH, Jantos CA (2001) Heparan sulfate-like glycosaminoglycan is a cellular receptor for Chlamydia pneumoniae. J Infect Dis 184: 181-187.

60. Kobayashi M, Ishida K, Matsuo J, Nakamura S, Nagasawa A, et al. (2011) Chlamydophila pneumoniae attachment and infection in low proteoglycan expressing human lymphoid Jurkat cells. Microb Pathog 51: 209-216.

61. Isaacs RD (1994) Borrelia burgdorferi bind to epithelial cell proteoglycans. J Clin Invest 93: 809-819.

62. Leong JM, Wang H, Magoun L, Field JA, Morrissey PE, et al. (1998) Different classes of proteoglycans contribute to the attachment of Borrelia burgdorferi to cultured endothelial and brain cells. Infect Immun 66: 994-999.

63. Fischer JR, Parveen N, Magoun L, Leong JM (2003) Decorin-binding proteins $\mathrm{A}$ and $\mathrm{B}$ confer distinct mammalian cell type-specific attachment by Borrelia burgdorferi, the Lyme disease spirochete. Proc Natl Acad Sci USA. 100: 7307-7312.

64. Fischer JR, LeBlanc KT, Leong JM (2006) Fibronecting binding protein BBK32 of the Lyme disease spirochete promotes bacterial attachment to glycosaminoglycans. Infect Immun 74: 435-441.

65. Menozzi FD, Pethe K, Bifani P, Soncin F, Brennan MJ, et al. (2002) Enhanced bacterial virulence through exploitation of host glycosaminoglycans. Mol Microbiol 43: 1379-1386.

66. Nam EJ, Park PW (2012) Shedding of cell membrane-bound proteoglycans. Methods Mol Biol 836: 291-305.

67. Park PW, Pier GB, Preston MJ, Goldberger O, Fitzgerald ML, et al. (2000) Syndecan-1 shedding is enhanced by LasA, a secreted virulence factor of Pseudomonas aeruginosa. J Biol Chem 275: 3057-3064.

68. Schmidtchen A, Frick IM, Björck L (2001) Dermatan sulphate is released by proteinases of common pathogenic bacteria and inactivates antibacterial alpha-defensin. Mol Microbiol 39: 708-713.

69. Sheth HB, Lee KK, Wong WY, Srivastava G, Hindsgaul O, et al. (1994) The pili of Pseudomonas aeruginosa strains PAK and PAO bind specifically to the carbohydrate sequence beta GalNAc(1-4)beta Gal found in glycosphingolipids asialo-GM1 and asialo-GM2. Mol Microbiol 11:715-723.

70. Plotkowski MC, Costa AO, Morandi V, Barbosa HS, Nader HB, et al. (2001) Role of heparan sulphate proteoglycans as potential receptors for non-piliated Pseudomonas aeruginosa adherence to non-polarised airway epithelial cells. J Med Microbiol 50: 183-190.

71. Bucior I, Mostov K, Engel JN (2010) Pseudomonas aeruginosa-mediated damage requires distinct receptors at the apical and basolateral surfaces of the polarized epithelium. Infect Immun 78: 939-953.

72. Hayashida A, Amano S, Park PW (2011) Syndecan-1 promotes Staphylococcus aureus corneal infection by counteracting neutrophilmediated host defense. J Biol Chem 286: 3288-3297.
73. Hess DJ, Henry-Stanley MJ, Erlandsen SL, Wells CL (2006) Heparan sulfate proteoglycans mediate Staphylococcus aureus interactions with intestinal epithelium. Med Microbiol Immunol 195: 133-141.

74. Menozzi FD, Reddy VM, Cayet D, Raze D, Debrie AS, et al. (2006). Mycobacterium tuberculosis heparin-binding haemagglutinin adhesin (HBHA) triggers receptor-mediated transcytosis without altering the integrity of tight junctions. Microbes Infect 8:1-9.

75. Sheehan B, Kocks C, Dramsi S, Gouin E, Klarsfeld AD, et al. (1994) Molecular and genetic determinants of the Listeria monocytogenes infectious process. Curr Top Microbiol Immunol 192: 187-216.

76. Alvarez-Domínguez C, Vázquez-Boland JA, Carrasco-Marín E, LópezMato P, Leyva-Cobián F (1997) Host cell heparan sulfate proteoglycans mediate attachment and entry of Listeria monocytogenes, and the listerial surface protein ActA is involved in heparan sulfate receptor recognition. Infect Immun 65: 78-88.

77. Henry-Stanley M, Hess DJ, Erickson E, Garni RM, Wells C (2003) Role of heparan sulfate in interactions of Listeria monocytogenes with enterocytes. Med Microbiol Immunol 192: 107-115.

78. Henry-Stanley MJ, Hess DJ, Erlandsen SL, and Wells CL (2005) Ability of the heparan sulfate proteoglycan syndecan-1 to participate in bacterial translocation across the intestinal epithelial barrier. Shock 24: 571-576.

79. Pizarro-Cerdá J, Cossart P (2006) Subversion of cellular functions by Listeria monocytogenes. J Pathol 208: 215-223.

80. Frick IM, Schmidtchen A, Sjöbring U (2003) Interactions between M proteins of Streptococcus pyogenes and glycosaminoglycans promote bacterial adhesion to host cells. Eur J Biochem 270: 2303-2311.

81. Tonnaer EL, Hafmans TG, Van Kuppevelt TH, Sanders EA, Verweij PE, et al. (2006) Involvement of glycosaminoglycans in the attachment of pneumococci to nasopharyngeal epithelial cells. Microbes Infect 8: 316-322.

82. Baron MJ, Bolduc GR, Goldberg MB, Aupérin TC, Madoff LC (2004) Alpha C protein of group B Streptococcus binds host cell surface glycosaminoglycan and enters cells by an actin-dependent mechanism. J Biol Chem 279: 24714-24723.

83. Chang YC, Wang Z, Flax LA, Xu D, Esko JD, et al. (2011) Glycosaminoglycan binding facilitates entry of a bacterial pathogen into central nervous systems. PLoS Pathog 7: e1002082.

84. Sava IG, Zhang F, Toma I, Theilacker C, Li B, et al. (2009) Novel interactions of glycosaminoglycans and bacterial glycolipids mediate binding of enterococci to human cells. J Biol Chem 284: 18194-18201.

85. Baldassarri L, Bertuccini L, Creti R, Filippini P, Ammendolia MG, et al. (2005) Glycosaminoglycans mediate invasion and survival of Enterococcus faecalis into macrophages. J Infect Dis 191: 1253-1262.

86. Diederich AK, Wobser D, Spiess M, Sava IG, Huebner J, et al. (2014) Role of glycolipids in the pathogenesis of Enterococcus faecalis urinary tract infection. PLoS One 9: e96295.

87. Andreu A, Stapleton AE, Fennell CL, Hillier SL, Stamm WE (1995) Hemagglutination, adherence, and surface properties of vaginal Lactobacillus species. J Infect Dis 171: 1237-1243.

88. Boris S, Suárez JE, Barbés C (1997) Characterization of the aggregation promoting factor from Lactobacillus gasseri, a vaginal isolate. J Appl Microbiol 83: 413-420.

89. Boris S, Suárez JE, Vázquez F, Barbés C (1998) Adherence of human vaginal lactobacilli to vaginal epithelial cells and interaction with uropathogens. Infect Immun 66: 1985-1989.

90. Greene JD, Klaenhammer TR (1994) Factors involved in adherence of lactobacilli to human Caco-2 cells. Appl Environ Microbiol 60: 4487-4494.

91. Lee HS, Han SY, Ryu KY, Kim DH (2009) The degradation of glycosaminoglycans by intestinal microflora deteriorates colitis in mice. Inflammation 32: 27-36.

92. Nelson A, Berkestedt I, Schmidtchen A, Ljunggren L, Bodelsson M (2008) Increased levels of glycosaminoglycans during septic shock: relation to mortality and the antibacterial actions of plasma. Shock 30 : 623-627. 